\title{
Updated atmospheric speciated mercury emissions from iron and steel production in China during 2000-2015
}

\author{
Qingru Wu ${ }^{1,2}$, Wei Gao ${ }^{1,2}$, Shuxiao Wang ${ }^{1,2}$, and Jiming Hao ${ }^{1,2}$ \\ ${ }^{1}$ School of Environment and State Key Joint Laboratory of Environment Simulation and Pollution Control, \\ Tsinghua University, Beijing 100084, China \\ ${ }^{2}$ State Environmental Protection Key Laboratory of Sources and Control of Air Pollution Complex, Beijing 100084, China \\ Correspondence to: Shuxiao Wang (shxwang@tsinghua.edu.cn)
}

Received: 31 January 2017 - Discussion started: 27 March 2017

Revised: 25 July 2017 - Accepted: 26 July 2017 - Published: 6 September 2017

\begin{abstract}
Iron and steel production (ISP) is one of the significant atmospheric $\mathrm{Hg}$ emission sources in China. Atmospheric mercury (Hg) emissions from ISP during 2000-2015 were estimated by using a technology-based emission factor method. To support the application of this method, databases of $\mathrm{Hg}$ concentrations in raw materials, technology development trends, and $\mathrm{Hg}$ removal efficiencies of air pollution control devices (APCDs) were constructed through national sampling and literature review. $\mathrm{Hg}$ input to ISP increased from $21.6 \mathrm{t}$ in 2000 to $94.5 \mathrm{t}$ in 2015 . In the various types of raw materials, coking coal and iron concentrates contributed $35-46$ and $25-32 \%$ of the total $\mathrm{Hg}$ input. Atmospheric $\mathrm{Hg}$ emissions from ISP increased from $11.5 \mathrm{t}$ in 2000 to $32.7 \mathrm{t}$ in 2015 with a peak of $35.6 \mathrm{t}$ in 2013. Pollution control promoted the increase in average $\mathrm{Hg}$ removal efficiency, from $47 \%$ in 2000 to $65 \%$ in 2015 . During the study period, sinter/pellet plants and blast furnaces were the largest two emission processes. However, emissions from roasting plants and coke ovens cannot be ignored, which accounted for 22$34 \%$ of ISP's emissions. Overall, $\mathrm{Hg}$ speciation shifted from 50/44/6 (gaseous elemental $\mathrm{Hg}\left(\mathrm{Hg}^{0}\right) /$ gaseous oxidized $\mathrm{Hg}$ $\left(\mathrm{Hg}^{\mathrm{II}}\right) /$ particulate-bound $\left.\mathrm{Hg}\left(\mathrm{Hg}_{\mathrm{p}}\right)\right)$ in 2000 to $40 / 59 / 1$ in 2015, which indicated a higher proportion of $\mathrm{Hg}$ deposition around the emission points. Future emissions of ISP were expected to decrease based on the comprehensive consideration crude-steel production, steel scrap utilization, energy saving, and pollution control measures.
\end{abstract}

\section{Introduction}

China is the largest iron and steel production (ISP) country in the world. Crude-steel production has increased from $127 \mathrm{Mt}$ in 2000 to $804 \mathrm{Mt}$ in 2015 (CISIA, 2001-2016). Rapid economic development has led to large emissions of air pollutants including mercury $(\mathrm{Hg})$ emissions of ISP (Liu et al., 2016; K. Wang et al., 2016; Wang et al., 2014). To reduce $\mathrm{Hg}$ pollution, it is important to quantify atmospheric $\mathrm{Hg}$ emissions from ISP.

According to existing national inventories, atmospheric $\mathrm{Hg}$ emissions from ISP increased from $4.9 \mathrm{t}$ in 1999 to $25.5 \mathrm{t}$ in 2010 (AMAP/UNEP, 2008; Streets et al., 2005; Wu et al., 2006; L. Zhang et al., 2015). In these studies, Hg emissions were determined as the product of crude-steel production, with a unique emission factor of $0.04 \mathrm{~g}$ per ton of steel produced which did not consider the emissions from roasting plants and coke ovens (two processes of ISP). However, field experiments in China's ISP indicated that these two processes are significant for $\mathrm{Hg}$ emissions. Emissions from coke ovens accounted for $17-49 \%$ of the total $\mathrm{Hg}$ emissions of ISP (F. Y. Wang et al., 2016). Thus, these two processes are potentially important in shaping the trends in ISP $\mathrm{Hg}$ emissions. Later long-term emission inventories revised the unique emission factor with dynamic factors by adopting a transformed normal distribution function (Tian et al., 2015; K. Wang et al., 2016; Wu et al., 2016). Such a method was based on the assumption that the emission factor was gradually improved according to the simulation curve and attempted to simulate the impact of technology improvement and pollution control on emission factor variation. However, 
the emission factors were not actually linked to technology and air pollution control devices (APCDs) directly. Thus, the simulated emission factors may be quite different from the actual situation during a certain period (e.g., 10 years) when technology and APCDs experienced dramatic change (Wu et al., 2016), especially against the background of the increasing requirements of environmental protection in China in the past decades (MEP, 2011; NEA, 2014; SC, 2013). A recent global $\mathrm{Hg}$ assessment report applied a technology-based emission factor method to estimate the emissions of global ISP, including China's (AMAP/UNEP, 2013). However, most of the parameters were from developed countries, which may impact the accuracy of emissions from developing countries such as China. In addition, emissions from roasting plants and arc steelmaking processes (using scrap to produce steel) were not calculated in the report.

The dominant parameters of a technology-based emission factor included $\mathrm{Hg}$ removal efficiencies of APCDs and $\mathrm{Hg}$ concentrations in raw materials (Wu et al., 2016, 2012; L. Zhang et al., 2015). As for $\mathrm{Hg}$ removal efficiencies of APCDs, we hypothesized that the use of data from recent field experiments on atmospheric $\mathrm{Hg}$ emission characteristics in China's ISP will provide a foundation for the technologybased emission factor model (Wu et al., 2016, 2012; L. Zhang et al., 2015). However, current studies cannot support the construction of $\mathrm{Hg}$ concentration databases for raw materials. Various raw materials were used in ISP, covering iron concentrates, iron block, alloy materials, steel scrap, coal, and additives (mainly limestone and dolomite). Field experiments in three of China's steel smelters indicated that the concentrations of iron concentrates were in the range of 23-66 ng g ${ }^{-1}$ (F. Y. Wang et al., 2016; Y. H. Zhang et al., 2015). However, the Hg concentration data from limited samples may lead to large uncertainty in the national inventory. Many studies have reported $\mathrm{Hg}$ concentrations in coal (Swaine, 1992; Tian et al., 2010; USGS, 2004; Zhang et al., 2012). But the specific requirement of low-sulfide coal (less than $1.2 \%$ ) in ISP may lead to different $\mathrm{Hg}$ concentrations in the consumed coal (Tao and Wang, 1994) since low-sulfide coal was generally accompanied by low Hg (Zhang, 2012). Only a few studies have reported $\mathrm{Hg}$ concentrations in steel scrap and dolomite. Therefore, constructing $\mathrm{Hg}$ concentration databases of raw materials was the basis for applying a technology-based emission factor model for China's ISP.

In this study, a technology-based emission factor model was constructed to estimate atmospheric $\mathrm{Hg}$ emissions from China's ISP. To fulfill this aim, raw materials consumed in steel smelters have been sampled and $\mathrm{Hg}$ concentrations have been analyzed to construct the $\mathrm{Hg}$ concentration databases. Up-to-date $\mathrm{Hg}$ removal efficiencies from field experiments and the development trends in production technology and APCDs have been summarized to support the application of an emission factor model.

\section{Methodology}

\subsection{Technology-based emission factor model for ISP}

Generally speaking, the ISP method includes the longprocess steelmaking method and the short-process steelmaking method. The long-process steelmaking method includes roasting plants, coke ovens, sinter/pellet plants, blast furnaces, and oxygen steelmaking (Fig. 1). The short-process steelmaking method produces crude steel mainly from steel scrap in the arc steelmaking process directly.

Thus, atmospheric Hg emissions from ISP by province can be calculated as follows.

$$
\begin{aligned}
& E_{i}(t)=E_{i, l}(t)+E_{i, s}(t) \\
& \quad=E_{i, l, r}(t)+E_{i, l, c}(t)+E_{i, l, p}(t)+E_{i, l, b}(t)+E_{i, l, o}(t) \\
& \quad+E_{i, s, a}(t),
\end{aligned}
$$

where $E$ is atmospheric $\mathrm{Hg}$ emissions from ISP (in t); $i$ is province; $t$ refers to studied year; " $l$ " and " $s$ " refer to the long- and short-process steelmaking method; " $r$ ", " $c$ ", " $p$ ", " $b$ ", " $o "$, and " $a$ " refer to roasting plants, coke ovens, sinter/pellet plants, blast furnaces, oxygen steelmaking, and arc steelmaking, respectively.

For each process $x$, the technology-based emission factor and speciated $\mathrm{Hg}$ emissions can be calculated as follows.

$$
\begin{aligned}
& \mathrm{EF}_{i, x, k}(t)=\sum_{j} C_{i, x, j} \times M_{i, x, j}(t) \times S_{i}(t)^{-1} \times \gamma_{x} \\
& \times \sum_{m} \theta_{m}(t) \times \delta_{k . m} \times\left(1-\eta_{m}\right) \times 1000^{-1} \\
& E_{i, x, k}(t)=\mathrm{EF}_{i, x, k}(t) \times S_{i}(t),
\end{aligned}
$$

where $\mathrm{EF}$ is emission factor $\left(\mathrm{g} \mathrm{t}^{-1}\right) ; x$ is the studied process; $k$ is speciated $\mathrm{Hg}$; $j$ is the type of consumed raw material; $C$ is $\mathrm{Hg}$ concentration in the consumed raw material (ng g ${ }^{-1}$; see Sect. 2.2.1); $M$ is the consumption of raw material (Mt; see Sect. 2.2.2); $S$ is the production of crude steel (Mt; see Sect. 2.2.2). $\gamma$ is the $\mathrm{Hg}$ release rate, which means the percentage of $\mathrm{Hg}$ released to flue gas from raw material (\%). $\mathrm{Hg}$ release rates were collected from field experiment studies (Table S1 in the Supplement). They were $98 \%$ for roasting plants, $80 \%$ for coke ovens, $85 \%$ for sinter/pellet plants, $98 \%$ for blast furnaces, $80 \%$ for oxygen steelmaking furnaces, and $95 \%$ for arc steelmaking furnaces. $m$ refers to the type of APCD combination (see Sect. 2.2.3); $\delta$ is the proportion of different $\mathrm{Hg}$ speciation (see Sect. 2.2.3; \%); $\theta$ is the application rate of different APCD combinations (see Sect. 2.2.3; \%); $\eta$ is $\mathrm{Hg}$ removal efficiency (see Sect. 2.2.3; $\%)$.

\subsection{Parameters for model}

\subsubsection{Hg concentrations in raw materials}

For the long-process steelmaking method, the dominant raw materials includes iron concentrates, iron block, coal, lime- 


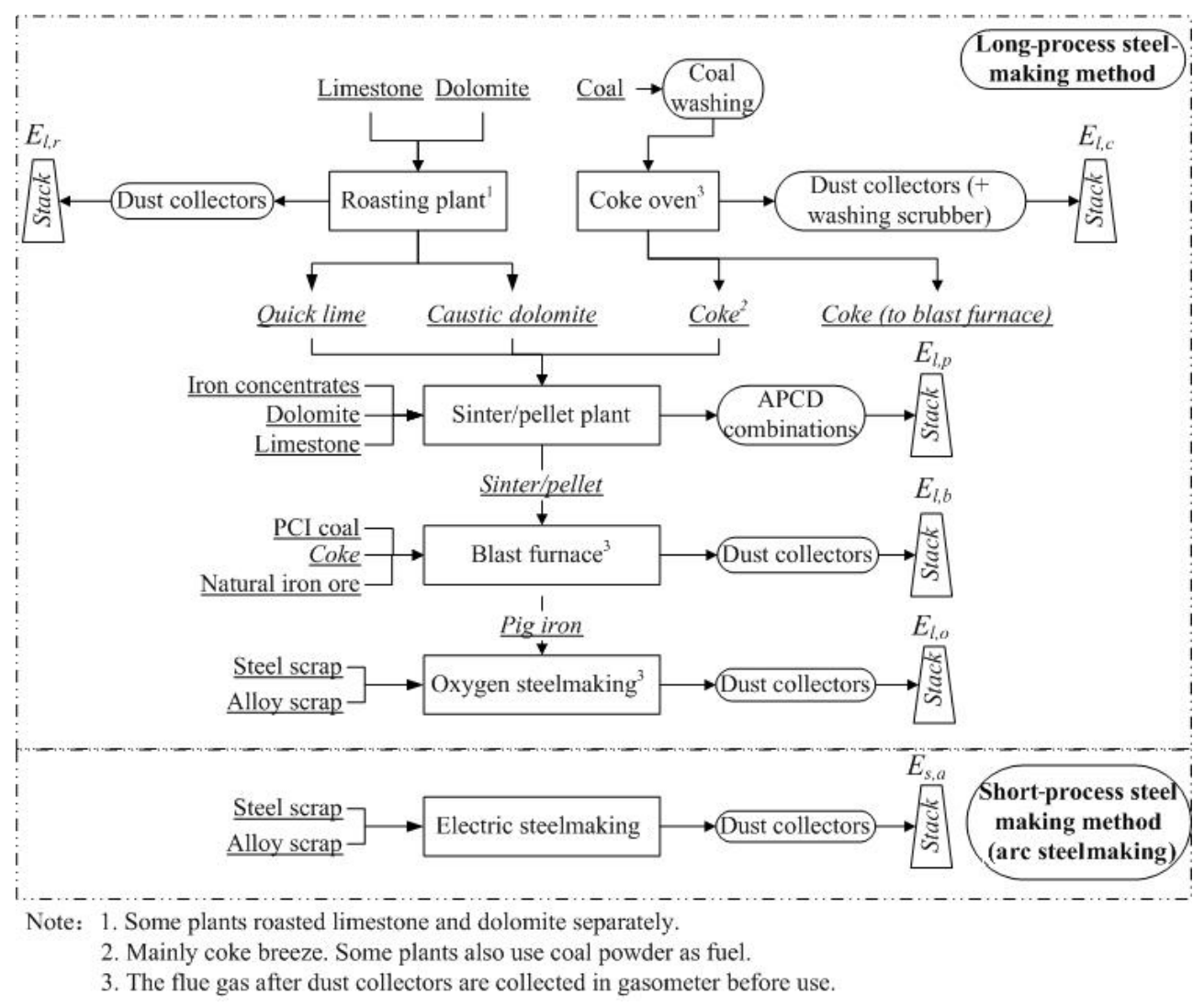

Figure 1. Flow chart of ISP processes.

stone, dolomite, alloy, and steel scrap (Fig. 1). In the roasting plants, limestone and dolomite are roasted together or separately to make quicklime and caustic dolomite. In the coke ovens, washed coal is used to produce coke. In the sinter/pellet plants, iron-containing materials (mainly iron concentrates), quicklime, caustic dolomite, and produced coke (mainly coke breeze) are mixed to produce sintered/pellet blocks, which are used as raw materials with coal and produced coke in the blast furnace. The produced pig iron from blast furnaces and additional scraps are used to produce steel in the oxygen steelmaking processes. For the short-process steelmaking method, the arc steelmaking process is applied to produce steel by mainly using scraps as raw materials. In each process, $\mathrm{Hg}$ input due to the use of intermediated products (e.g., quicklime, caustic dolomite, and coke) was calculated by using the mass balance method (Wu et al., 2012).

National sampling and $\mathrm{Hg}$ concentration analysis were conducted to construct the $\mathrm{Hg}$ concentration databases for the consumed raw materials. The sampling, preparation, and analysis methods were described in detail in our previous studies (Wu et al., 2012; Zhang et al., 2012). Lumex 915M + pyro attachment (with a detection limit of $0.5 \mathrm{ng} \mathrm{g}^{-1}$ ) was applied to analyze $\mathrm{Hg}$ concentration by using the U.S. EPA method 7473 (US EPA, 1998). The number of samples and the $\mathrm{Hg}$ concentrations in dominant raw materials by province is shown in Table 1 . National $\mathrm{Hg}$ concentrations (median value) in the consumed iron ores were 20 (0.6-387) $\mathrm{ng} \mathrm{g}^{-1}$, which was lower than the median value of 30 (0.6-600) $\mathrm{ng} \mathrm{g}^{-1}$ used in the global assessment report (AMAP/UNEP, 2013). Overall, Hg concentrations in the consumed coking coal $\left(82 \mathrm{ng} \mathrm{g}^{-1}\right)$ and pulverized coal injection (PCI) coal $\left(73 \mathrm{ng} \mathrm{g}^{-1}\right)$ were lower than the 170 (82248) $\mathrm{ng} \mathrm{g}^{-1}$ (Zhang, 2012) used in China's coal combustion sectors but higher than the 55 (50-60) $\mathrm{ng} \mathrm{g}^{-1}$ of global assessment report. $\mathrm{Hg}$ concentrations in the limestone were 18 (0.9-2753) $\mathrm{ng} \mathrm{g}^{-1}$. Although the median value was lower than value of $30(20-50) \mathrm{ng} \mathrm{g}^{-1}$ applied in the global assessment report, the variation range was much wider according to our analysis. $\mathrm{Hg}$ concentrations (median value) in the dolomite and iron block were 9 and $19 \mathrm{ng} \mathrm{g}^{-1}$. In the oxygen and arc steelmaking processes, the main iron-containing materials were steel scrap, alloy scrap, and pig iron. $\mathrm{Hg}$ concentrations (median value) in steel scrap and alloy scrap were 48 and $2 \mathrm{ng} \mathrm{g}^{-1}$, while the concentrations in pig iron were less than the detection limit. For provinces with at least $15 \mathrm{sam}-$ ples, the distribution characteristics of $\mathrm{Hg}$ concentrations of the samples were generated by using the batch fit function of Crystalball software. Otherwise, Hg concentrations were assumed to fit a normal distribution. 


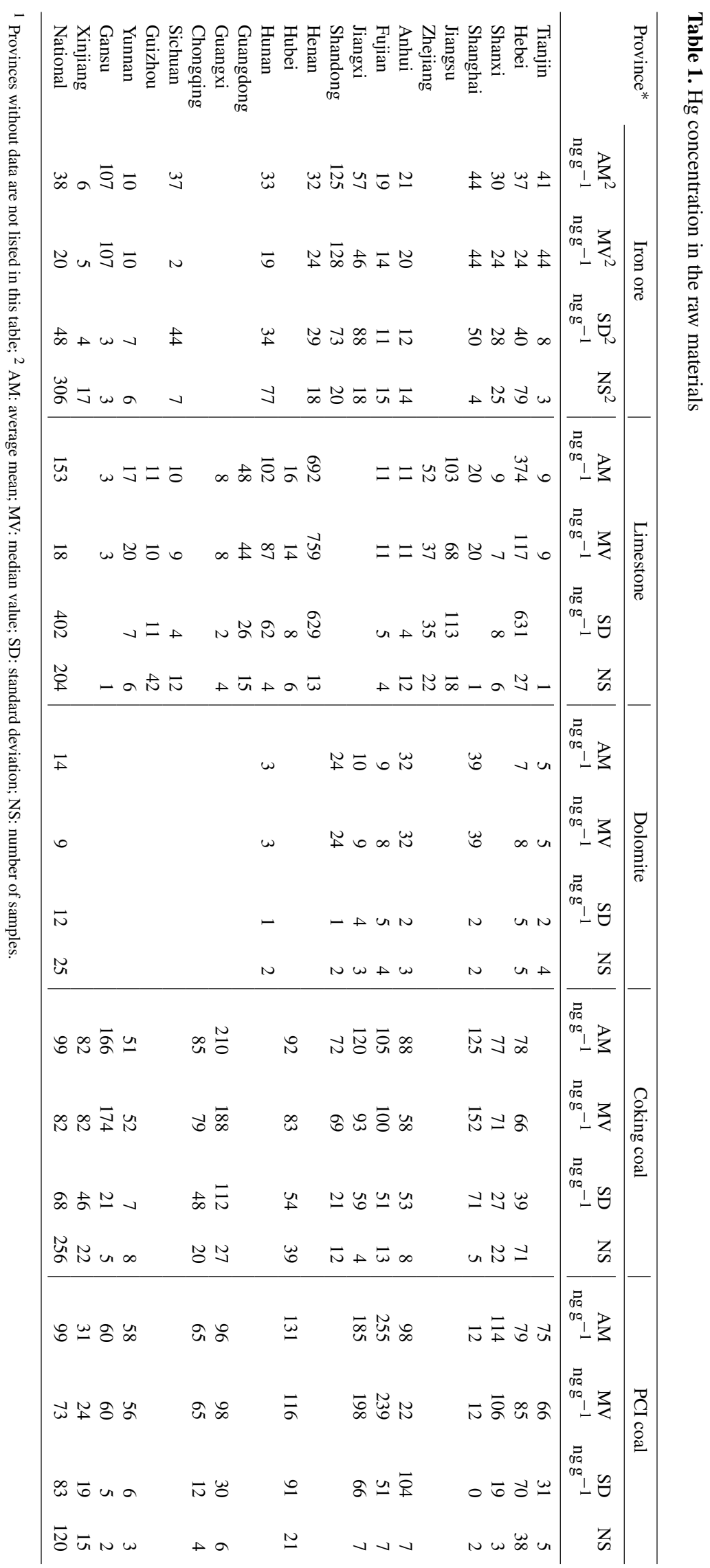




\subsubsection{Provincial consumption of raw materials}

Provincial consumption of raw materials in 2015 is shown in Table S2. National limestone consumption was converted from quicklime consumption (Ma, 2011) by using the factor of $1.95 \mathrm{t}$ of limestone to produce $1 \mathrm{t}$ of quicklime (CISIA, 2001-2016) (Table S3). National dolomite consumption was derived from China steel statistics report (Ma, 1995) according to the production trends in crude steel. Limestone and dolomite can be consumed in the roasting and sinter/pellet plants. In the sinter/pellet plants, additive (including limestone and dolomite) consumption was approximately $153.9 \mathrm{~kg}$ per ton of sinter produced or $10.5 \mathrm{~kg}$ per ton of pellet produced (CISIA, 2001-2016). We assumed that $88 \%$ of the additives were limestone and $12 \%$ were dolomite according to field experiments (F. Y. Wang et al., 2016). The remaining limestone and dolomite were consumed in the roasting plants. Provincial consumption of limestone and dolomite was distributed according to the proportion of provincial pig iron production in national production (Table S2). Provincial pig iron production was collected directly from yearbooks (CISIA, 2001-2016).

Provincial coking coal consumption was converted from provincial coke consumption (CISIA, 2001-2016). Generally, there were two main types of coke production methods, including the machining coke production method and indigenous coke production methods. Coal consumption was $1.35 \mathrm{t}$ to produce $1 \mathrm{t}$ of machining coke or $1.65 \mathrm{t}$ to produce $1 \mathrm{t}$ of indigenous coke (UNEP, 2013; Wang, 1991). The produced coke was used as raw material in both sinter/pellet plants and blast furnaces. Provincial coke consumption in blast furnaces was converted according to a coke ratio of $363-388 \mathrm{~kg}$ of coke per ton of pig iron produced (CISIA, 2001-2016). The remaining coke was assumed to be consumed in sinter/pellet plants.

National iron concentrate consumption was converted from sinter/pellet production. Approximately 0.91-0.92 and $0.96-0.97 \mathrm{t}$ of iron concentrates were needed to produce $1 \mathrm{t}$ of sinter and $1 \mathrm{t}$ of pellet, respectively (CISIA, 2001-2016). National sinter and pellet production was obtained directly from yearbooks (CISIA, 2001-2016), and provincial data were converted according to provincial pig iron production.

National PCI coal consumption in blast furnaces was collected from the national energy statistical yearbook (NESA, 2001-2016), and the provincial data were converted according to provincial pig iron production. The iron block consumption in blast furnaces was converted from pig iron production by using the factor of $156 \mathrm{~kg}$ of iron block per ton of pig iron produced (CISIA, 2001-2016).

The steel scrap was consumed in both the oxygen and arc steelmaking process. The consumption of steel scrap in the oxygen and arc steelmaking process was approximately 59.4 and $361.9 \mathrm{~kg}$ per ton of crude steel produced. Alloy consumption per ton of crude steel was $16-17 \mathrm{~kg}$ in the oxygen steelmaking process and $140-156 \mathrm{~kg}$ in the arc oxygen mak- ing process. The oxygen and arc steel production was collected directly from yearbooks (CISIA, 2001-2016). Based on these ratios, provincial steel scrap and alloy consumption was converted from provincial crude-steel production.

\subsubsection{Application rate, $\mathrm{Hg}$ removal efficiency, and $\mathrm{Hg}$ speciation}

In the roasting plants, blast furnaces, and steelmaking process, dust collectors such as a venturi, cyclone (CYC), wet scrubber (WS), electrostatic precipitator (ESP), and fabric filter (FF) are used for flue gas dedusting. In the coke oven process, washed coal is consumed and the flue gas was cleaned with dust collectors or with additional washing scrubbers. Flue gas from sinter/pellet plants was generally cleaned with dust collectors. Additional flue gas desulfurization (FGD) towers have been gradually applied since 2010. It should be noted that, after the use of dust collectors, the flue gas was generally collected as coal gas in a gasometer. However, rare APCDs are applied during the coal gas usage process. Thus, we assumed that all $\mathrm{Hg}$ in the coal gas was emitted to air. The application rates of different APCD combinations during 2005-2010 were collected, grouped by process, from previous studies (Wang et al., 2014; Zhao et al., 2013). The data of 2000-2004 and 2011-2015 were mainly derived from yearbooks (CISIA, 2001-2016; NBS, 2001-2016) (Table $\mathrm{S} 4) . \mathrm{Hg}$ removal efficiencies and speciation profiles of APCDs (Table S4) were collected from field experiments and the literature on emission studies (Gao, 2016; F. Y. Wang et al., 2016; Y. H. Zhang et al., 2015). The distribution characteristics of $\mathrm{Hg}$ removal efficiencies were assumed to fit normal distribution characteristics.

\subsection{Uncertainty analysis}

A Monte Carlo simulation was introduced to estimate the uncertainty in emissions. A detailed description of the simulation processes has been reported in our previous studies (Hui et al., 2016; Wu et al., 2016; L. Zhang et al., 2015). In this study, the (P50-P10)/P50 and (P90-P50)/P50 values were still regarded as the lower and upper limits of uncertainties an $80 \%$ confidence degree, where P10, P50, and P90 meant that the probabilities of actual results lower than the corresponding values were 10,50 , and $90 \%$, respectively.

\section{Results and discussion}

\subsection{Hg input trends}

$\mathrm{Hg}$ input to ISP increased from $21.6 \mathrm{t}$ in 2000 to $94.5 \mathrm{t}$ in 2015 (Fig. 2). The peak in Hg input was in 2014 when crudesteel production reached its highest value (Table S3). During 2000-2014, the average annual growth rate (AAGR) of $\mathrm{Hg}$ input was $11 \%$, while $\mathrm{Hg}$ input reduced by $3 \%$ from 2014 to 2015 . In the various types of raw materials, coking coal and 


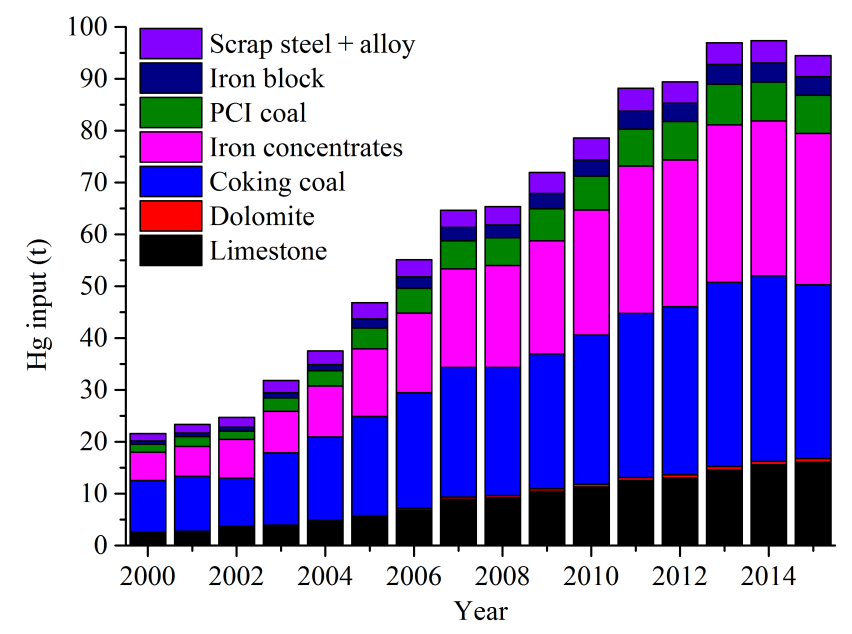

Figure 2. $\mathrm{Hg}$ input trends by material.

iron concentrates contributed the largest amount of $\mathrm{Hg}$ input, accounting for 35-46 and $25-32 \%$ of the total, respectively. $\mathrm{Hg}$ input due to the use of coking coal increased from $9.9 \mathrm{t}$ in 2000 to $33.5 \mathrm{t}$ in 2015 . Hg input with iron concentrates increased at an AAGR of $12 \%$ from 2000 and reached $29.2 \mathrm{t}$ in 2015. The PCI coal brought approximately $6-9 \%$ of $\mathrm{Hg}$ to ISP. $\mathrm{Hg}$ in the additives (including limestone and dolomite) contributed $12-18 \%$ of total $\mathrm{Hg}$ input. $\mathrm{Hg}$ in iron blocks was in the range of 0.6-3.6 t. Hg input due to the use of steel scrap and alloy was $4.1 \mathrm{t}$ in 2015 , accounting for $4 \%$ of the national total. However, steel scrap and alloy contributed $7 \%$ of total crude-steel production in 2015 (CISIA, 2011-2016).

\subsection{Hg emission trends}

\subsubsection{Hg emission trends by process}

Atmospheric $\mathrm{Hg}$ emissions from ISP increased from $11.5 \mathrm{t}$ in 2000 to $32.7 \mathrm{t}$ in 2015 (Fig. 3). The peak in emissions was in 2013 when the emissions reached 35.6t. In 2015, emissions from the long-process steelmaking method and shortprocess steelmaking were 32.2 and $0.5 \mathrm{t}$, accounting for 98.3 and $1.7 \%$ of the national total, respectively. Thus, emissions from long-process steelmaking were still the dominant emission process of China's ISP. Among the processes, emissions from sinter/pellet plants accounted for $42-49 \%$ of the annual total. Their emissions increased from $4.8 \mathrm{t}$ in 2000 at an AAGR of $10.1 \%$ and reached $15.9 \mathrm{t}$ in 2015 . Blast furnaces were also significant $\mathrm{Hg}$ emitters. Their emissions increased from $1.9 \mathrm{t}$ in 2000 to $7.9 \mathrm{t}$ in 2015 at an AAGR of $10.0 \%$. The AAGR for roasting plants and coke ovens was 8.3 and $1.2 \%$. In 2015, emissions from both roasting plants and coke ovens were $7.0 \mathrm{t}$.

The slower AAGR of $\mathrm{Hg}$ emissions (7.2\%) than of crudesteel production (13\%) reflected the impact on $\mathrm{Hg}$ emission reduction due to energy saving and environmental protection in ISP. On one hand, Hg input to produce unitary crude steel

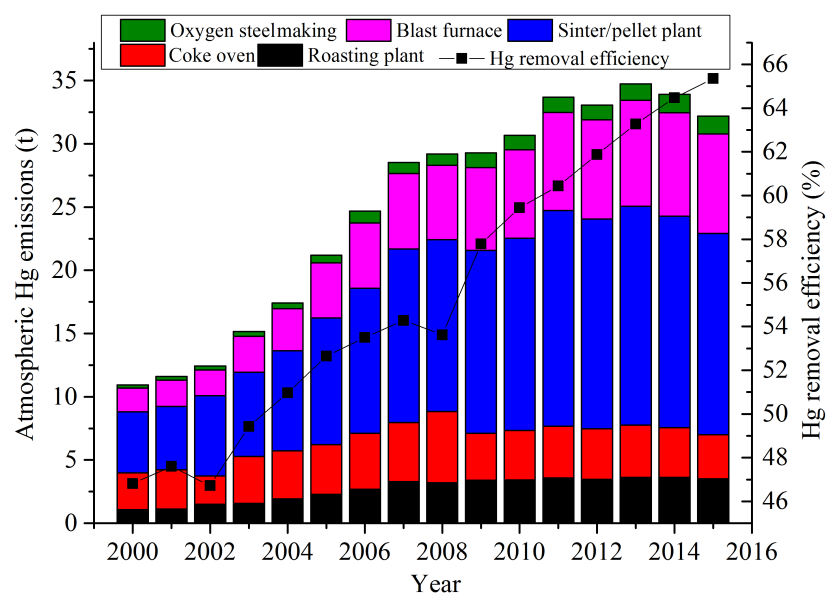

Figure 3. $\mathrm{Hg}$ emission trends by process and $\mathrm{Hg}$ removal efficiency.

decreased from 0.17 to $0.12 \mathrm{~g} \mathrm{t}^{-1}$, which was mainly the result of the improvement of coke production efficiency and energy utilization efficiency of sinter/pellet plants and blast furnaces. Since 2004, the indigenous coke production method with high coal consumption has been gradually replaced by the machine coke production method. The coke ratio in sinter/pellet plants has been reduced from approximately $388 \mathrm{~kg}$ per ton of pig iron produced in 2000 to $363 \mathrm{~kg} \mathrm{t}^{-1}$ in 2015 (CISIA, 2001-2016). On the other hand, the improvement of APCDs increased the overall $\mathrm{Hg}$ removal efficiency from $47 \%$ in 2000 to $65 \%$ in 2015 (Fig. 3). APCDs for coke ovens have shown the largest $\mathrm{Hg}$ removal efficiencies (64$87 \%$ ), while pollution control in sinter/pellet plants contributed most to the rapid $\mathrm{Hg}$ reduction speed during 20002015. The replacement of CYC and WS with ESP and FF in sinter/pellet plants improved $\mathrm{Hg}$ removal efficiency from $21 \%$ in 2000 to $44 \%$ in 2010. The application of FGD in addition to dust collectors was the main driver of $\mathrm{Hg}$ reduction in the sinter/pellet process during 2011-2015. Hg removal efficiency in sinter/pellet plants was 53\% in 2015.

\subsubsection{Hg emission trends by province}

Provincial Hg emissions in 2000, 2005, 2010, and 2015 are shown in Table 2. In 2000, Shanxi, Shanghai, Henan, Hebei, and Shandong were the top five largest emitters with emissions larger than $1 \mathrm{t}$. Emissions from these five provinces contributed $58 \%$ of national $\mathrm{Hg}$ emissions. Following these five provinces were Liaoning, Beijing, Gansu, Jiangsu, and Jiangxi. The summation of the emissions from all of the above 10 provinces resulted in $9.0 \mathrm{t}$, accounting for $78 \%$ of national emissions in 2000. At the provincial level, we noted significant differences in $\mathrm{Hg}$ emission trends during the past 16 years. The AAGR of provincial $\mathrm{Hg}$ emissions varied from -40 to $26 \%$. A negative AAGR existed in Beijing and Shanghai provinces, the two most economically developed regions in China. $\mathrm{Hg}$ abatement in these two re- 
Table 2. Provincial Hg emissions during 2000-2015.

\begin{tabular}{lrrrrr}
\hline Province* & \multicolumn{5}{c}{ Atmospheric Hg emissions (kg) } \\
\cline { 2 - 6 } & 2000 & 2005 & 2010 & 2015 & AAGR \\
\hline Beijing & 432.0 & 316.1 & 132.9 & 0.0 & $-40 \%$ \\
Tianjin & 260.0 & 482.0 & 863.4 & 688.9 & $7 \%$ \\
Hebei & 1202.0 & 4016.0 & 6672.3 & 7129.3 & $13 \%$ \\
Shanxi & 1587.3 & 2214.2 & 2075.2 & 1792.3 & $1 \%$ \\
Inner Mongolia & 287.5 & 477.8 & 667.7 & 753.8 & $7 \%$ \\
Liaoning & 845.8 & 1171.1 & 1679.3 & 1563.4 & $4 \%$ \\
Jilin & 109.5 & 190.9 & 282.8 & 267.9 & $6 \%$ \\
Heilongjiang & 71.4 & 171.4 & 307.3 & 180.2 & $6 \%$ \\
Shanghai & 1532.6 & 1155.7 & 1021.2 & 703.6 & $-5 \%$ \\
Jiangsu & 304.5 & 1149.5 & 1891.4 & 2519.4 & $15 \%$ \\
Zhejiang & 75.9 & 139.8 & 356.2 & 362.0 & $11 \%$ \\
Anhui & 252.5 & 399.4 & 572.6 & 586.6 & $6 \%$ \\
Fujian & 67.9 & 150.2 & 243.8 & 309.2 & $11 \%$ \\
Jiangxi & 292.1 & 701.4 & 1054.0 & 984.8 & $8 \%$ \\
Shandong & 1122.5 & 3965.4 & 6017.7 & 6051.1 & $12 \%$ \\
Henan & 1259.8 & 2172.9 & 3495.3 & 4049.9 & $8 \%$ \\
Hubei & 268.0 & 363.7 & 467.6 & 376.7 & $2 \%$ \\
Hunan & 239.2 & 512.1 & 713.7 & 627.2 & $7 \%$ \\
Guangdong & 131.7 & 286.6 & 339.7 & 395.9 & $8 \%$ \\
Guangxi & 82.4 & 236.8 & 423.6 & 538.9 & $13 \%$ \\
Hainan & 0.1 & 0.5 & 0.0 & 3.1 & $26 \%$ \\
Chongqing & 106.2 & 121.7 & 168.4 & 142.3 & $2 \%$ \\
Sichuan & 224.6 & 353.7 & 400.2 & 377.5 & $4 \%$ \\
Guizhou & 100.9 & 235.4 & 204.1 & 187.4 & $4 \%$ \\
Yunnan & 99.0 & 299.4 & 382.9 & 283.0 & $7 \%$ \\
Shaanxi & 75.8 & 222.7 & 395.9 & 689.5 & $16 \%$ \\
Gansu & 372.5 & 528.5 & 612.8 & 708.1 & $4 \%$ \\
Qinghai & 12.2 & 10.6 & 64.5 & 24.8 & $5 \%$ \\
Ningxia & 10.0 & 28.9 & 72.6 & 139.8 & $19 \%$ \\
Xinjiang & 50.1 & 97.0 & 286.8 & 294.6 & $13 \%$ \\
\hline Total & 11476 & 22171 & 31866 & 32732 & $7 \%$ \\
\hline & & & & & \\
\hline
\end{tabular}

* Provinces without data are not listed in this table.

gions was mainly caused by the reduction in crude-steel production, which was transferred to nearby provinces such as Hebei, Zhejiang, Jiangsu, and Shandong. Thus, Hg emissions in these nearby provinces all presented high AAGRs of more than $10 \%$. In 2015, the largest five $\mathrm{Hg}$ emission provinces changed to Hebei, Shandong, Henan, Jiangsu, and Shanxi provinces. Emissions from these provinces reached $21.5 \mathrm{t}$, accounting for $68 \%$ of national emissions. Liaoning, Jiangxi, Inner Mongolia, Gansu, and Shanghai were also in the list of the top 10 largest emitters.

\subsubsection{Hg emission trends by species}

Overall, the $\mathrm{Hg}$ speciation profile of ISP experienced great change during the study period from 50/44/6 (gaseous elemental $\mathrm{Hg}\left(\mathrm{Hg}^{0}\right) /$ gaseous oxidized $\mathrm{Hg}\left(\mathrm{Hg}^{\mathrm{II}}\right) /$ particulatebound $\left.\mathrm{Hg}\left(\mathrm{Hg}_{\mathrm{p}}\right)\right)$ in 2000 to 40/59/1 in 2015 (Fig. 4). The proportion of $\mathrm{Hg}^{\mathrm{II}}$ increased by $15 \%$, whereas both the $\mathrm{Hg}^{0}$ and $\mathrm{Hg}_{\mathrm{p}}$ proportion showed a decreasing trend. Such a shift indicated a higher deposition proportion of $\mathrm{Hg}$ around the emission points since $\mathrm{Hg}^{\mathrm{II}}$ has a larger deposition velocity

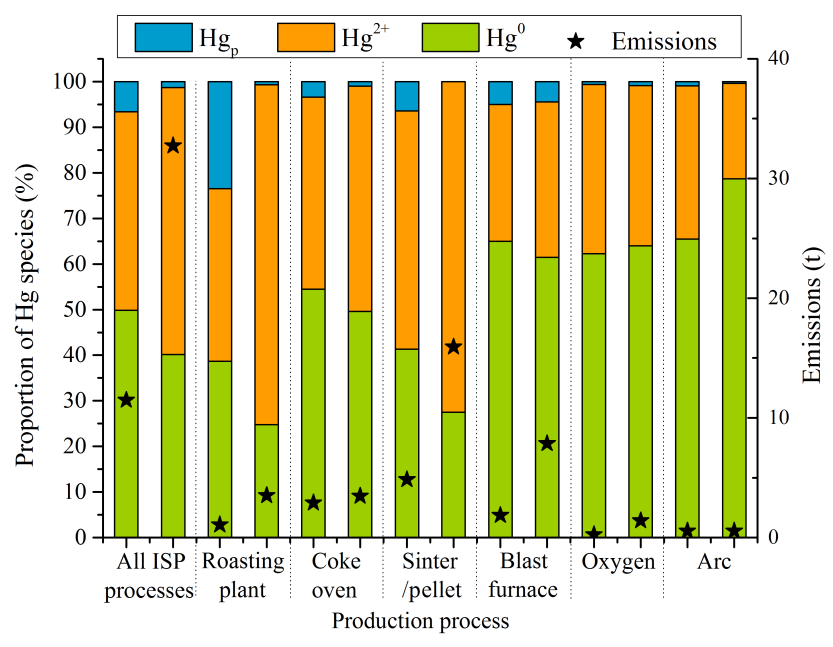

Figure 4. Proportion of different $\mathrm{Hg}$ species (f1or each process, the left and right column represent the data in 2000 and 2015, respectively).

and higher water solubility. For long-process steelmaking, the $\mathrm{Hg}$ speciation profile shifted from $49 / 44 / 7$ in 2000 to 39/60/1. The speciation shift in roasting plants was mainly impacted by the replacement of WS and CYC with FF, which increased the emitted $\mathrm{Hg}^{\mathrm{II}}$ proportion from 38 to $75 \%$. Initially, the replacement of the indigenous coke production method by the machine coke production method mainly contributed to the $\mathrm{Hg}^{\mathrm{II}}$ proportion increase from 42 to $52 \%$. However, the gradual installation of a WS in addition to a cooler for the air pollution control of the machine coke production method further washed $\mathrm{Hg}^{\mathrm{II}}$ and reduced the $\mathrm{Hg}^{\mathrm{II}}$ proportion to $49 \%$ in 2015 . The $\mathrm{Hg}^{\mathrm{II}}$ proportion in the exhaust gas of sinter/pellet plants has increased by $20 \%$. The increase in the $\mathrm{Hg}^{\mathrm{II}}$ proportion in sinter/pellet plants was mainly impacted by the substitution of WS by ESP, FF, ESP+WFGD, or ESP+DFGD+FF, (DFGD: dry flue gas desulfurization system; WFGD: wet flue gas desulfurization system) which generally emitted gas with a higher $\mathrm{Hg}^{\mathrm{II}}$ proportion (Table S4). An increase in the $\mathrm{Hg}^{\mathrm{II}}$ emission proportion in blast furnaces was due to a higher $\mathrm{Hg}^{\mathrm{II}}$ emission proportion after FF than venturi. In the oxygen steelmaking process, the $\mathrm{Hg}$ speciation profile remained almost unchanged. For short-process steelmaking, $\mathrm{Hg}^{0}$ was the dominant speciation during the whole study period and the proportion of $\mathrm{Hg}^{0}$ increased from $66 \%$ in 2000 to $79 \%$ in 2015 .

\subsection{Uncertainty analysis}

In 2015, the overall uncertainty in atmospheric $\mathrm{Hg}$ emissions from ISP was in the range of $(-29,77 \%)$ (Fig. 5). The emission uncertainties in ISP were $(-80,100 \%)$ in the study of Zhang et al. (2015) and $(-100,100 \%)$ in the study of Streets et al. (2005) and Wu et al. (2006). The improvement in emission estimation of this study was the result of better knowl- 


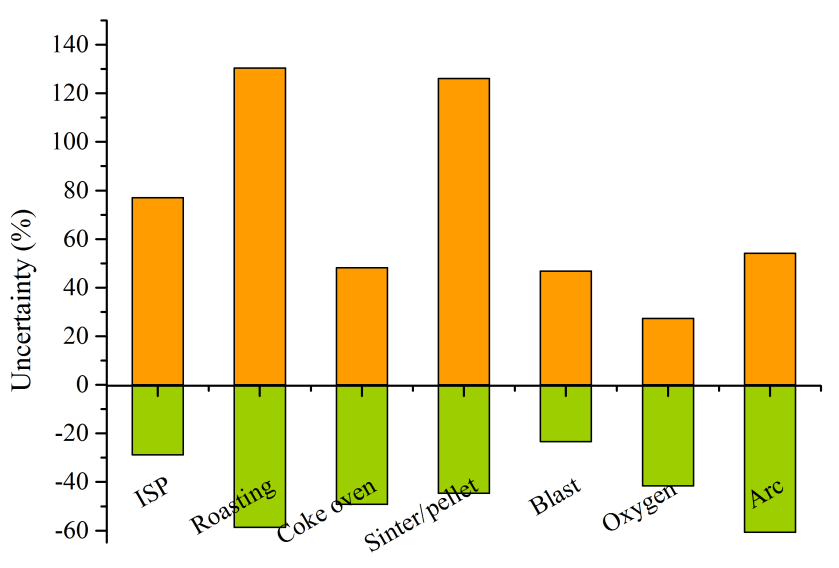

Figure 5. Uncertainty analysis.

edge of the $\mathrm{Hg}$ concentrations of raw materials and $\mathrm{Hg}$ removal efficiencies of APCDs. In all ISP processes, the largest uncertainties existed in emissions from roasting plants $(-59$, $130 \%)$ and the sinter/pellet process $(-45,126 \%)$. These were mainly due to larger distribution range of $\mathrm{Hg}$ concentrations in limestone and iron ore as well as the $\mathrm{Hg}$ removal efficiencies of APCDs. The uncertainties in $\mathrm{Hg}$ emissions from other processes were much lower: $(-49,48 \%)$ for coke ovens, $(-23,46 \%)$ for blast furnaces, $(-41,27 \%)$ for oxygen steelmaking, and $(-60,54 \%)$ for arc steelmaking.

\subsection{Comparison and implications}

Due to the complicated ISP processes and limitations of data availability, the process combinations considered in different inventories were divided into four types (Fig. 6) (AMAP/UNEP, 2008, 2013; K. Wang et al., 2016; Wu et al., 2016, 2006; L. Zhang et al., 2015). The first type (green symbols in Fig. 6) included sinter plants and blast furnaces, which were the basic assumption in the emission inventories of Wu et al. (2006), L. Zhang et al. (2015), and AMAP/UNEP (2008). In these studies, a unique emission factor of $0.0400 \mathrm{~g} \mathrm{t}^{-1}$ was applied (Table S5), and their emissions were similar in the same inventory year. Our emissions for this process combination were almost the same as the above estimations around 2005. However, the gap grew with time when FGD was gradually applied in sinter/pellet plants. Therefore, the emission factor for this type of combination was reduced from $0.0527 \mathrm{~g} \mathrm{t}^{-1}$ in 2000 to $0.0296 \mathrm{~g} \mathrm{t}^{-1}$ in 2015 (Table S5). The second type (orange symbols in Fig. 6) also consisted of steelmaking in addition to the first type. Our estimation was much higher than that in the study of K. Wang et al. (2016) because the emission factors applied in K. Wang's study were mainly derived from European technical report (EMEP/CORINAIR, 2001; EMEP/EEA, 2013). However, the technology applied in Europe may be better than in China. For example, the emission factor of $0.00019 \mathrm{~g} \mathrm{t}^{-1}$ applied for blast furnaces with FF was used as the best emission

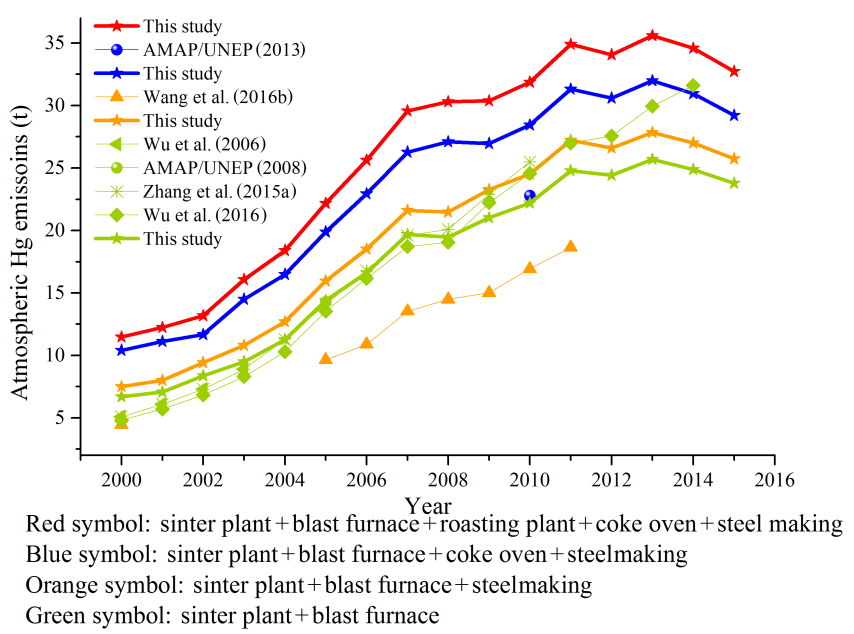

Figure 6. Atmospheric $\mathrm{Hg}$ emissions of ISP in different studies.

factor in K. Wang's (2016) study. However, the combination of a WS and a venturi scrubber was the dominant APCD type for China's blast furnaces (Zhao et al., 2013), the Hg removal efficiency of which was lower than that of FF. The third type of process combination (blue symbols in Fig. 6) also consisted of coke ovens as part of ISP in addition to the second type. Lower $\mathrm{Hg}$ emissions estimated by AMAP/UNEP (2013) were due to their lower $\mathrm{Hg}$ concentration in coal. In addition, although different processes were considered in the global report, a unique APCD profile was applied for different processes. The application proportion of ESP+FGD reached $55 \%$. However, FGDs were mainly installed in sinter/pellet plants but rarely applied in other processes. Thus, the emissions estimated by the global report were lower than our estimation. The fourth type (red symbols in Fig. 6) also considered the emissions from the roasting process where emissions accounted for $9-11 \%$ of total emissions.

The comparison of emissions from different types of process combinations in this study indicates the significance of including emissions from roasting plants and coke ovens in the ISP emission inventories. The proportion of emissions from these two processes accounted for 22-34\% of ISP's emissions during the whole study period. In addition, these two processes were important in shaping the trends in ISP $\mathrm{Hg}$ emissions. For example, $\mathrm{Hg}$ emissions of all processes showed an increase during 2007-2008 (red line in Fig. 6). However, if these two processes are not considered, we will observe a decreasing trend (green and orange lines in Fig. 6). Moreover, given the impact of APCDs on the emission estimation, inventories in ISP should also apply distinct APCD profiles for different processes so as to reduce the uncertainty in inventories.

Future $\mathrm{Hg}$ emission for ISP was forecasted to decrease based on a comprehensive consideration of dominant parameters (e.g., steel production, air pollution control measures) in the technology-based method and the emission trends from 
China's ISP during 2000-2015. On the one hand, the annual growth rate of crude-steel production reduced from $14.2 \%$ in 2000-2014 to $1.24 \%$ in 2015-2016. Thus, China's ISP has passed the quick growth period. During 2014-2016, the crude-steel production was around $810 \mathrm{Mt}$. It was expected that the peak in crude-steel production would be in the range of 669-1092 Mt (Zhong, 2013) and the crude-steel production in 2020 will be in the range of 750-800 Mt (MIIT, 2016). Therefore, the peak in crude-steel production may have arrived or be coming. And slowly decreasing crude-steel production was expected after the peak according to the development trends in mineral resource consumption rules in developed countries. In addition, with the coming of a highyield period of steel scrap production (Guo and Wei, 2010), the application proportion of the short-process steelmaking method is expected to increase, which will indirectly reduce the necessity to produce steel by means of the long-process steelmaking method. The replacement of the steel production method will also be one driver of $\mathrm{Hg}$ emission reduction considering the lower $\mathrm{Hg}$ emission factors of the short process. Moreover, energy consumption is required to be reduced by more than $10 \%$ during 2016-2020 (MIIT, 2016), and energy savings will be a long-term strategy in China. The improvement of energy efficiency in the main processes will reduce energy consumption ( $\mathrm{Li}$ et al., 2015) and further lead to the reduction in $\mathrm{Hg}$ input. On the other hand, emissions of pollutants (eg., $\mathrm{SO}_{2}, \mathrm{NO}_{x}$, and $\mathrm{PM}$ ) are required to be reduced by at least $15 \%$ for ISP before 2020 in China (MIIT, 2016). To fulfill this goal, corresponding emission standards have been issued (Wu, 2013), which will accelerate the application of improved APCDs. During 2010-2015, the increase in $\mathrm{SO}_{2}$ emission limits from 1500 to $200 \mathrm{mg} \mathrm{m}^{-3}$ promoted the large-scale application of desulfurization devices in the sinter/pellet plants of ISP. After 2015, ISP will move forward to $\mathrm{NO}_{x}$ control by using related technologies such as selective catalytic reduction (SC, 2013), the synergic $\mathrm{Hg}$ removal efficiencies of which have been proved in other industries (Wang et al., 2010). If we assumed that the crude-steel production reached a conservative value of $1000 \mathrm{Mt}$ and that advanced dust collectors (ESP or FF), desulfurization towers, and denitration technologies were fully applied in ISP, atmospheric $\mathrm{Hg}$ emissions in ISP will be reduced to $27 \mathrm{t}$ in 2020. Thus, a decreasing trend will be expected from 2015 to 2020. Such a conclusion is the opposite of that drawn by the study using the transformed normal distribution method $(\mathrm{Wu}$ et al., 2016). In this study, the transformed normal distribution function was applied to estimate atmospheric $\mathrm{Hg}$ emissions from ISP. By using such a semiquantitative method, the emission factor in $2020\left(0.0402 \mathrm{~g} \mathrm{t}^{-1}\right.$ for the long process and $0.0211 \mathrm{~g} \mathrm{t}^{-1}$ for short process) was almost the same as that in $2015\left(0.0403 \mathrm{~g} \mathrm{t}^{-1}\right.$ for the long process and $0.0212 \mathrm{~g} \mathrm{t}^{-1}$ for the short process). Thus, atmospheric $\mathrm{Hg}$ emissions in 2020 will almost depend on crude-steel production and the emissions in 2020 will reach $40 \mathrm{t}$ at the conservative situation.
Therefore, the technology-based emission factor method will provide more objective forecasts of future emissions.

\section{Conclusions}

In this study, atmospheric $\mathrm{Hg}$ emissions from ISP during 2000-2015 were estimated by using a technology-based emission factor method with up-to-date parameters. The input of $\mathrm{Hg}$ as an impurity in the raw materials of ISP increased from $21.6 \mathrm{t}$ in 2000 to $94.5 \mathrm{t}$ in 2015 . In the various types of raw materials, coking coal and iron concentrates contributed to the largest amount of $\mathrm{Hg}$ input: $35-46$ and $25-32 \%$ of the national total, respectively. Atmospheric $\mathrm{Hg}$ emissions from ISP increased from $11.5 \mathrm{t}$ in 2000 to the peak of $35.6 \mathrm{t}$ in 2013 and then reduced to $32.7 \mathrm{t}$ in 2015 . Overall, $\mathrm{Hg}$ speciation shifted from $50 / 44 / 6\left(\mathrm{Hg}^{0} / \mathrm{Hg}^{\mathrm{II}} / \mathrm{Hg}_{\mathrm{p}}\right)$ in 2000 to $40 / 59 / 1$ in 2015. In the coming years, emissions from ISP are expected to decrease due to the projection of $\mathrm{Hg}$ input reduction and the improvement of APCDs.

In 2015, emissions from the long-process steelmaking method and short-process steelmaking were 32.2 and $0.5 \mathrm{t}$, accounting for 98.3 and $1.7 \%$ of the national total, respectively. Sinter/pellet plants and blast furnaces were the largest two emission processes, accounting for 49 and $24 \%$ of national emissions, respectively. However, emissions from roasting and coke ovens deserve attention because their emissions accounted for $22 \%$ of national emissions. The largest five $\mathrm{Hg}$ emission provinces were Hebei, Henan, Shandong, Jiangsu, and Shanxi provinces. Emissions from these provinces reached $21.5 \mathrm{t}$, accounting for $68 \%$ of national emissions.

In this study, we applied the technology-based emission factor method for a better quantification of $\mathrm{Hg}$ in ISP and atmospheric $\mathrm{Hg}$ emissions from different processes of ISP. Compared with previous studies, the uncertainty in atmospheric $\mathrm{Hg}$ emissions from ISP has been greatly reduced through a better understanding of $\mathrm{Hg}$ flow in ISP. This method has provided a more objective estimation of current emissions and a forecast of future emissions. However, with the continuous change in APCD combinations, extensive and dedicated field experiments are still required to generate a suitable database of $\mathrm{Hg}$ removal efficiencies for improved APCDs in the future.

Data availability. All data are available from the authors upon request.
The Supplement related to this article is available online at https://doi.org/10.5194/acp-17-10423-2017- supplement. 
Competing interests. The authors declare that they have no conflict of interest.

Acknowledgements. This study was supported by the Major State Basic Research Development Program of China (973 Program) (2013CB430001), the Natural Science Foundation of China (21607090), and the China Postdoctoral Science Foundation (2016T90103, 2016M601053)

Edited by: Aurélien Dommergue

Reviewed by: two anonymous referees

\section{References}

Arctic Monitoring and Assessment Programme and United Nations Environment Programme (AMAP/UNEP): Technical background report to the global atmospheric mercury assessment, AMAP/UNEP, Geneva, Switzerland, 2008.

Arctic Monitoring and Assessment Programme and United Nations Environment Programme (AMAP/UNEP): Technical background report for the global mercury assessment, AMAP/UNEP, Geneva, Switzerland, 2013.

China Iron and Steel Industry Association (CISIA): China Steel yearbook, CISIA, Beijing, China, 2001-2016.

European Monitoring and Evaluation Programme/Core Inventory of Air Emissions Project (EMEP/CORINAIR): Emission inventory guidebook, EMEP/CORINAIR, Copenhagen, Denmark, 2001.

European Monitoring and Evaluation Programme/European Economic Area (EMEP/EEA): Air pollutant emission inventory guidebook 2013, EMEP/EEA, Copenhagen, Danmark, 2013.

Gao, W.: Study on atmospheric mercury emission characteristics for iron and steel producing process in China, Tsinghua University, School of Environment, Beijing, China, 2016.

Guo, T. L. and Wei, L. Q.: Development direction of the recycling industry of secondary zinc resources, China Nonfer. Metal., 4, 56-59, 2010.

Hui, M. L., Wu, Q. R., Wang, S. X., Liang, S., Zhang, L., Wang, F. Y., Lenzen, M., Wang, Y. F., Xu, L. X., Lin, Z. T., Yang, H., Lin, Y., Larssen, T., Xu, M., and Hao, J. M.: Mercury Flows in China and global drivers, Environ. Sci. Technol., 51, 222-231, 2016.

Li, X. C., Gao, X., and Jiang, X. D.: Analysis on potential of energy conservation of Chinese steel industry in the 13th five-year period, The tenth annual conference of China steel and the sixth annual academic conference of Baogang, Shanghai, Beijing, 201510-21, 2015.

Liu, H., Fu, M. L., Jin, X. X., Shang, Y., Shindell, D., Faluvegi, G., Shindell, C., and He, K. B.: Health and climate impacts of oceangoing vessels in East Asia, Nature climate change, 6, 1037-1041, 2016.

Ma, H. L.: China steel statistics, Development and Planning Division of Ministry of Metallurgical, Beijing, China, 1995.

Ma, J.: Review and projection of technology development of lime used in China's steel industry, China steel, 6, 17-20, 2011.

Ministry of Environmental Protection (MEP): "Twelfth Five-year" plan for the comprehensive prevention and control of heavy metal pollution, MEP, Beijing, China, 2011.
Ministry of industry and information Technology (MIIT): Adjustment and upgrading plan of iron and steel industry (2016-2020), MIIT, Beijing, China, 2016.

National Statistical Bureau of China (NBS): China Environmental Statistics Yearbook, NBS, Beijing, China, 2001-2016.

National Energy Administration (NEA): Action plan of coal clean utilization, NEA, Beijing, China, 2014.

National Energy Statistical Agency of China (NESA): China Energy Statistical Yearbook, NESA, Beijing, China, 2001-2016.

State Council of the People's Republic of China (SC): Action plan of national air pollution prevention and control, SC, Beijing, China, 2013.

Streets, D. G., Hao, J. M., Wu, Y., Jiang, J. K., Chan, M., Tian, H. Z., and Feng, X. B.: Anthropogenic mercury emissions in China, Atmos. Environ., 39, 7789-7806, 2005.

Swaine, D. J.: Environmental aspects of trace-elements in coal, Environ. Geochem. Health, 14, p. 2, 1992.

Tao, S. R. and Wang, Y. J.: Imapct on the economic benefits of metallurgy industry from coke coal quality, Coal Proce. Compre. Utiliz., 4, 17-20, 1994.

Tian, H. Z., Wang, Y., Xue, Z. G., Cheng, K., Qu, Y. P., Chai, F. H., and Hao, J. M.: Trend and characteristics of atmospheric emissions of $\mathrm{Hg}$, As, and Se from coal combustion in China, 1980-2007, Atmos. Chem. Phys., 10, 11905-11919, https://doi.org/10.5194/acp-10-11905-2010, 2010.

Tian, H. Z., Zhu, C. Y., Gao, J. J., Cheng, K., Hao, J. M., Wang, K., Hua, S. B., Wang, Y., and Zhou, J. R.: Quantitative assessment of atmospheric emissions of toxic heavy metals from anthropogenic sources in China: historical trend, spatial distribution, uncertainties, and control policies, Atmos. Chem. Phys., 15, 1012710147, https://doi.org/10.5194/acp-15-10127-2015, 2015.

United Nations Envieonment Programme (UNEP): Toolkit for identification and quantification of mercury releases. Guideline for inventory level 2, version 1.3., 2013.

United States Environmental Portection Agency (US EPA): Method 7473: $\mathrm{Hg}$ in solids and solutions by thermal decomposition amalgamation and atomic absorption spectrophotometry, US EPA, Washinton D. C., United States, 1998.

United States Geological Survey (USGS): Mercury content in coal mines in China, Reston, Virginia, United States, 2004.

Wang, F. Y., Wang, S. X., Zhang, L., Yang, H., Gao, W., Wu, Q. R., and Hao, J. M.: Mercury mass flow in iron and steel production process and its implications for mercury emission control, J. Environ. Sci., 43, 293-301, 2016.

Wang, K., Tian, H. Z., Hua, S. B., Zhu, C. Y., Gao, J. J., Xue, Y. F., Hao, J. M., Wang, Y., and Zhou, J. R.: A comprehensive emission inventory of multiple air pollutants from iron and steel industry in China: Temporal trends and spatial variation characteristics, Sci. Total Environ., 559, 7-14, 2016.

Wang, S. X., Zhang, L., Li, G. H., Wu, Y., Hao, J. M., Pirrone, N., Sprovieri, F., and Ancora, M. P.: Mercury emission and speciation of coal-fired power plants in China, Atmos. Chem. Phys., 10, 1183-1192, https://doi.org/10.5194/acp-10-1183-2010, 2010.

Wang, S. X., Zhao, B., Cai, S. Y., Klimont, Z., Nielsen, C. P., Morikawa, T., Woo, J. H., Kim, Y., Fu, X., Xu, J. Y., Hao, J. M., and He, K. B.: Emission trends and mitigation options for air pollutants in East Asia, Atmos. Chem. Phys., 14, 6571-6603, https://doi.org/10.5194/acp-14-6571-2014, 2014. 
Wang, Y. F.: Analysis on the harm of indigenous coking, Coal Eco. Res., 1, 1991.

Wu, Q. R., Wang, S. X., Zhang, L., Song, J. X., Yang, H., and Meng, Y.: Update of mercury emissions from China's primary zinc, lead and copper smelters, 2000-2010, Atmos. Chem. Phys., 12, 11153-11163, https://doi.org/10.5194/acp-12-111532012, 2012.

Wu, Q. R., Wang, S. X., Li, G. L., Liang, S., Lin, C.-J., Wang, Y. F., Cai, S. Y., Liu, K. Y., and Hao, J. M.: Temporal trend and spatial distribution of speciated atmospheric mercury emissions in China during 1978-2014, Environ. Sci. Technol., 50, 1342813435, 2016.

Wu, S. H.: Interpretation about "Emission Standards of Iron and Steel Industrial Pollutants”, Indus. Safety Environ. Pro., 39, 54 55, p. 95, 2013

Wu, Y., Wang, S. X., Streets, D. G., Hao, J. M., Chan, M., and Jiang, J. K.: Trends in anthropogenic mercury emissions in China from 1995 to 2003, Environ. Sci. Technol., 40, 5312-5318, 2006.

Zhang, L.: Emission characteristics and synergistic control strategies of atmospheric mercury from coal combustion in China, PhD Dissertation, Tsinghua University, School of Environment, Beijing, China, 2012.

Zhang, L., Wang, S. X., Meng, Y., and Hao, J. M.: Influence of mercury and chlorine content of coal on mercury emissions from coal-fired power plants in China, Environ. Sci. Technol., 46, 6385-6392, 2012.
Zhang, L., Wang, S. X., Wang, L., Wu, Y., Duan, L., Wu, Q. R., Wang, F. Y., Yang, M., Yang, H., Hao, J. M., and Liu, X.: Updated emission inventories for speciated atmospheric mercury from anthropogenic sources in China, Environ. Sci. Technol., 49, 3185-3194, 2015.

Zhang, Y. H., Zhang, C., Wang, D. Y., Luo, C., Yang, X., and Xu, F.: Characteristic of mercury emissions and mass balance of the typical iron and steel industry, Environ. Sci., 36, 4366-4374, 2015.

Zhao, B., Wang, S. X., Liu, H., Xu, J. Y., Fu, K., Klimont, Z., Hao, J. M., He, K. B., Cofala, J., and Amann, M.: NO $\mathrm{X}_{\mathrm{X}}$ emissions in China: historical trends and future perspectives, Atmos. Chem. Phys., 13, 9869-9897, https://doi.org/10.5194/acp13-9869-2013, 2013.

Zhong, X. G.: Research on historical development and market forecast of China's crude steel production, Indus. Econo., 7, 32-33, 2013. 